\section{Varying Opportunities to Respond to Improve Behavior of Elementary Students with Developmental Disabilities}

Teresa D. Bolt ${ }^{\mathrm{a}}$, Blake D. Hansen ${ }^{\mathrm{b}}$, Paul Caldarellac,*, K. Richard Young ${ }^{d}$, Leslie Williams ${ }^{e}$, Howard P. Wills ${ }^{f}$

\begin{tabular}{ll}
\hline Received: & 10 December 2018 \\
Revised: $\quad 27$ February 2019 \\
Accepted: $\quad 1$ March 2019 \\
ISSN: $1307-9298$ \\
Copyright @ IEJEE \\
www.iejee.com
\end{tabular}

DOI: 10.26822/iejee.2019450791

\begin{abstract}
This study investigated the effects of varying opportunities to respond when using a behavior management program with three elementary school students with developmental disabilities in a small group special education setting. These students exhibited both academic and behavioral difficulties. With the implementation of Class-Wide Function-Related Intervention Teams (CW-FIT) with low opportunities to respond (OTR), students increased their active engagement and correct responses, as well as decreased their disruptive behaviors. When CW-FIT with high OTR was implemented, students showed an even greater improvement than CW-FIT with low OTR. Higher rates of OTR resulted in higher levels of active engagement and correct responses and decreases in disruptive behavior for all three students. These results indicate that CW-FIT in combination with high OTR can help elementary school teachers manage students' behavior and increase students' correct responding when implemented in a small group special education setting.
\end{abstract}

Keywords: Elementary School, Special Education, Opportunities To Respond, Positive Reinforcement

\section{Introduction}

Challenging behavior and academic failure often co-occur in elementary school, especially for students with developmental disabilities (Desrochers \& Fallon, 2014). Specifically, students with autism spectrum disorders (ASD) and attention deficit/hyperactivity disorder (ADHD) often have difficulties with behavior. Such students demonstrate significantly higher levels of behavioral and emotional difficulties across areas such as attention problems and internalizing and externalizing behaviors than typically developing peers (Ashburner, Ziviani, \& Rodger, 2010).

Problem behavior does not only affect students, but also impacts teachers. There is an inverse relationship between the rate of challenging behavior and the rate of teacher instruction (Sutherland \& Wehby, 2001): Teachers provide more instruction to students without disruptive behavior than to students with disruptive behavior (Carr, Taylor, \& Robinson, 1991). This can be extremely detrimental to elementary students with developmental disabilities who already struggle with the academic instruction they receive. Due to the complicated relationship of problem behavior, academic success, and teacher instruction it is important for students with developmental disabilities to receive both academic and behavioral intervention.

In a meta-analysis of behavioral interventions used to decrease disruptive behavior, on average across studies, group contingencies were ranked the most effective (Stage \& Quiroz, 1997). Elementary school teachers use group contingencies to reward students based on the behavior of all the members of a group, thus motivating them to exhibit appropriate behavior. Additionally, several evidence-based practices to increase the academic success of students with challenging behavior were found to include direct social skill instruction, teacher praise and reinforcement, and increasing students' opportunities to respond (OTR) during instruction (Lewis, Hudson, Richter, \& Johnson, 2004).

\section{Opportunities to Respond}

OTR refers to the number of chances students are given to respond individually or as a group to questions from the teacher (Sutherland, Alder, \& Gunter, 2003). Increasing OTR has been found to be an effective practice for teachers (MacSuga-Gage \& Simonsen, 2015), as each student builds fluency with increased accuracy for correct responses. Studies have demonstrated a high correlation between high OTR and increased on-task behavior and decreased disruptive behavior for students with challenging behaviors (Conroy, Sutherland, Haydon, Stormont, \& Harmon, 2009). Carnine (1976) determined that increasing OTR in an elementary school classroom resulted in increased on-task behavior, increased correct response, and decreased rates of disruptive behaviors. West and Sloane (1986) examined the relationship between slow and fast presentation of OTR implemented with elementary school students who displayed behavioral problems and found high rates of OTR resulted in lower rates of disruptive behavior. Skinner and Shapiro (1989) found that high rates of OTR led to increased words read correctly and fewer words read incorrectly. Sutherland et al. (2003) examined the effects of OTR on correct academic responses and disruptive behavior for elementary students with emotional and behavioral disorders. They found that when OTR increased, time on task, teacher praise, and correct responses from students increased, while disruptive behavior decreased. Sutherland, Wehby, and Yoder (2002) found a positive correlation between high OTR, academic talk, and teacher praise in kindergarten thru $8^{\text {th }}$ grade self-contained classrooms for students with behavior and learning problems. Increased OTR resulted in higher use of many other

\footnotetext{
e*Corresponding Author: Paul Caldarella, Brigham Young University, Provo, Utah, USA. Phone: 801-422-5081. Email: paul caldarella@byu.edu

Teresa D. Bolt, Brigham Young University, Provo, Utah, USA. E-mail: teresabolt15@gmail.com

Blake D. Hansen, Brigham Young University, Provo, Utah, USA. E-mail: blake_hansen@byu.edu

¿ K. Richard Young, Brigham Young University, Provo, Utah, USA. E-mail: rkrichardyoung10@gmail.com

Leslie Williams, Brigham Young University, Provo, Utah, USA. E-mail: leslie_williams@byu.edu

fHoward P. Wills, University of Kansas, Lawrence, Kansas, USA. E-mail: hpwills@ku.edu
} 
evidence-based practices: for example, praise, error correction, and feedback. As students respond more frequently, teachers have more opportunities to provide feedback and praise. Students are able to gauge their own learning based on this feedback. These studies showed that increasing OTR increased on-task behavior as well as academic success of students with challenging behavior.

\section{Class-Wide Function-Related Intervention Teams}

One intervention that incorporates many evidence-based practices is Class-Wide Function-Related Intervention Teams (CW-FIT; Wills et al., 2010). CW-FIT is a group contingency behavior management program used to increase elementary students' on-task behavior and decrease disruptive behavior for the whole class, as well as individual students who may display problem behaviors. Students are taught specific social skills and earn group rewards for exhibiting the skills. CW-FIT integrates direct instruction on social skills, group contingencies, and behavior specific praise.

CW-FIT is designed based on a theory of change in which evidence-based classroom management procedures, and training thereof, leads to change in teacher practice that translates into improved outcomes for students. For example, direct instruction of functional social-communication skills has proven to be highly effective (Nelson et al., 1998; Lien-Thorne \& Kamps, 2005). Combined social skill teaching and delivery of reinforcers promotes improved behavioral outcomes (Kamps, Tankersley, \& Ellis, 2000). Group contingency programs, including reinforcers for appropriate rule following behavior, and mild, consistent consequences for inappropriate behavior, while focusing attention on appropriate behaviors, are especially effective with high risk students (Coogan, Kehle, Bray, \& Chafouleas, 2007; Thorne \& Kamps, 2008). The empirical evidence, as briefly described, support the conceptual logic linking CW-FIT components to the amelioration of disruptive behaviors and improved student on task behavior.

Kamps and colleagues (2015) conducted a randomized trial of CW-FIT with 17 elementary schools over a 4-year time period. Results showed classrooms that used CW-FIT had a significant increase of on-task behavior (52\% to $83 \%$ ) during the intervention phase, compared to the comparison group (50\% to 56\%). Average praise during intervention increased from 4 to 40 praises per 20 min interval, while the comparison teachers showed little change (4.46 to 4.62 praises). Average reprimands by CW-FIT teachers decreased from 7.48 to 4.45 per 20 min interval, while reprimands increased in the comparison group (8.42 to 9.49 ).

There is strong evidence across multiple studies supporting the effectiveness of CW-FIT in elementary general education classrooms (Caldarella, Williams, Hansen, \& Wills, 2015; Kamps et al., 2015; Kamps et al., 2011; Wills, Iwaszuk, Kamps, \& Shumate, 2014). These studies showed similar outcomes with increased on-task behavior, decreased disruptive behavior, and increased teacher praise in general education classrooms. This study extends these results by implementing the method in a special education small-group setting and additionally examining the effects of varied OTR, which may influence the effectiveness of the intervention (MacSuga-Gage \& Simonsen, 2015).

\section{Purpose and Research Questions}

Considerable evidence supports the effectiveness CW-FIT and of high rates of OTR used in elementary classes that include students who exhibit challenging behavior. However, none of the CW-FIT studies were performed with small groups in special education classrooms, nor were OTR examined. The purpose of this research was to determine whether CW-FIT would be effective when used with elementary students with academic and behavioral difficulties in a small group special education class and whether varying OTR would affect outcomes. To examine these practices in this context, the study sought to answer the following specific questions:

1. What are the comparative effects of low OTR versus high OTR with CW-FIT on active engagement, disruptive behaviors, and correct responses for elementary students with developmental disabilities in a small group special education setting?

2. What are the comparative effects of low OTR versus high OTR with CW-FIT on teacher praise and reprimands delivered to elementary students with developmental disabilities in a small group special education setting?

\section{Method}

\section{Setting and Participants}

This study took place in a six-week summer practicum conducted by special education teacher candidates for elementary students with developmental disabilities. The study was conducted in the western United States. The participating students received academic and behavioral instruction in a small class with a licensed special education teacher. The students then joined a class of approximately 15 students with three teacher candidates for specialties-physical education, music, and art. The female special education teacher with English as her first language had two years of experience teaching students with mild/moderate disabilities and prior to the study had completed training to implement CWFIT. Students participated in 25 min of reading instruction and 25 min of math instruction.

Participants included three elementary school students identified as having academic and behavioral difficulties. All three were classified under IDEA as having a developmental disability, and all had an Individualized Education Program (IEP) with behavioral goals. Students were nominated by staff of the participating school district to participate in the study due to behavioral challenges and academic needs. Students were enrolled in the study when parents provided signed consent before the practicum began.

Derek. Derek was an 8-year-old third grade boy with English as his first language. Derek received services in a self-contained special education classroom and resource classroom for 180 min per day under the classification of autism. Previous testing showed Derek performed in the low average range in math and reading according to the Woodcock-Johnson III Tests of Achievement (WJ-III; Woodcock, McGrew, \& Mather, 2001). Derek's cognitive assessment showed his abilities in the average range (full scale $I Q=102$ ) as measured by the Wechsler Intelligence Scale for Children-Fourth Edition (WISC-IV; Wechsler et al., 2003). The Behavioral Assessment System for Children, Second Edition (BASC-2: Reynolds, \& Kamphaus, 2006) showed Derek exhibited atypical behaviors and hyperactive behaviors in the clinically significant range. Though Derek had a behavioral intervention plan prior to this study to address non-compliance and independently entering the classroom, it was not used during the study.

Joshua. Joshua was an 11-year-old sixth grade boy with English as his first language. He received services in a self-contained special education classroom for 360 min per day under the classification of autism. Joshua had average basic reading skills (WJ-III standard score $[\mathrm{SS}]=90)$ and below average math skills (WJ-III SS =62). His cognitive abilities were 
below average (nonverbal IQ = 76) as measured by the Comprehensive Test of Nonverbal Intelligence (CTONI; Hammill, Pearson, \& Weiderholt, 1996). Joshua's behavior was considered clinically significant as measured by the BASC-2 (Behavior Symptom Index = 77). Prior to the study his behavior challenges involved frequent off-task behavior characterized by staring away from the teacher and neither responding to or engaging in the lesson.

Trent. Trent was a 10-year-old Caucasian male in fifth grade. Trent received services in a self-contained special education classroom and resource classroom for $180 \mathrm{~min}$ per day under the classification of other health impairment for ADHD. According to the WJ-III, Trent performed in the low average range in math (SS=84), writing ( $S S=84)$, and oral language $(S S=84)$. He had average cognitive abilities as measured by the WISC-IV (General Ability Index= 93). According to the BASC-2, his atypical behavior and attention problems were clinically significant. Trent had difficulty interacting with peers appropriately: He struggled to engage in appropriate conversation and often told peers what to do. He frequently called out during instruction.

\section{Data Collection}

Sessions were videotaped, and observers collected data from the recordings. Trained observers measured all dependent and independent variables using Multi-Option Observation System for Experimental Studies (MOOSES Tapp, Wehby, \& Ellis, 1995), recording frequency and duration behaviors. Frequency behaviors included correct responses and disruptive behaviors of the students, along with OTR, praise rates, and reprimand rates of the teacher. Duration behaviors included active and passive engagement and disengagement. Behaviors were measured for the first $15 \mathrm{~min}$ of the reading lesson.

Observer training. Three observers, each with undergraduate degrees in special education, communication disorders, or English education, were trained to calculate al variables. These participants memorized the definitions of all variables in order to effectively and efficiently collect data. During training, which included practice videos and live sessions, they reached $85 \%$ interobserver agreement (IOA) before beginning to code study data.

Treatment fidelity. A procedural fidelity checklist was completed by an observer following each session to ensure that CW-FIT was implemented as outlined. This checklist included procedures such as rules displayed, point goal displayed, and timer used. CW-FIT was implemented with 95\% accuracy over all sessions with a range of $72 \%-100 \%$. Interobserver agreement. IOA for direct observations was calculated by researchers during $41 \%$ of the sessions using the MOOSES program which divided the number of agreements by the number of agreements plus disagreements, then multiplied by 100 . Observers had to code the same behavior within a five second window to count as an agreement. The IOA for frequency behaviors was $85.23 \%$. IOA for duration behaviors was $96.23 \%$.

Social validity. Social validity was assessed by a student questionnaire that included three open-ended questions and two yes/no questions regarding their participation in CW-FIT. These questions were used to assess what the students liked or did not like about CW-FIT and whether they would recommend CW-FIT for their peers.

Data analysis. Data were gathered, graphed in Microsoft Excel 2013, and analyzed daily. This visual representation was used for phase change decisions, as well as overall analysis of intervention effectiveness. Graphed data were analyzed for changes in levels and trends, which helped in discerning variability within phases (Kennedy, 2005). Excessive data variability indicated a lack of experimental control, which caused difficulty in drawing conclusions from the data. When the data were stable, the study moved to the next phase. As the study continued through phases, the separation of phases was also examined. Data that distinctly separated between phases showed a stronger functional relationship between the dependent and independent variables. Overlap that prevented a clear separation between phases reflected another lack of experimental control, and minimal to no conclusions could be drawn from these data. Visual analysis was used to demonstrate experimental control as well as the effectiveness of the interventions.

\section{Student Measures}

Active engagement. Active engagement was defined as the student appropriately working on the assigned or approved activity (e.g., reading orally, writing words, answering questions). With MOOSES, the observers calculated the duration of active engagement, passive engagement (e.g., listening), and disengagement (e.g., not working appropriately). Active engagement was graphed as the percentage of time that the student was actively engaged. We focused on active engagement (versus passive engagement) as we expected the students to be actively participating in reading and responding.

Correct responses. During instruction observers used a frequency count to track the correct responses for individual students. A correct response was defined as when, within 5 seconds, the answer to academic instruction or academic behavior matched, or closely approximated, the answer on the teacher's worksheet or desired by the teacher. For example, if a teacher gave an OTR such as "What is the first word on the reading list?" and the student responded correctly within 5 seconds, a correct response was recorded. If the student responded incorrectly within 5 seconds, the observer marked the response incorrect. If the student didn't respond within 5 seconds, this was marked as a non-response. Correct responses also included behaviors such as writing spelling words or opening a book to the correct page after a teacher prompt. Percentage of correct responses was calculated as number of correct responses divided by number of correct responses plus incorrect responses plus non-responses.

Disruptive behavior. Disruptive behavior was defined as any physical or verbal behavior by a student that disrupts or distracts from instruction. Examples of disruptive behavior included talking out without raising a hand, arguing, name calling, being out of seat without permission, and using materials inappropriately (e.g., throwing, hitting, or tearing materials). Observers used a frequency count to track the occurrences of disruptive behaviors, coding each incidence as a single occurrence unless the topography changed (e.g., the student rocked in his chair and then began tapping a pencil) or the behavior ceased for at least three seconds and then resumed. In these instances, multiple disruptive behaviors were coded.

\section{Teacher Measures}

Opportunities to respond. OTR was defined as an instructional question or statement from the teacher to the group of students or an individual student requesting an academic response orally or publicly: "What is the first word on the reading list?" "What is the first step to solve the problem?" "Please tell us your answer for Problem 2." In this study, all OTR were given orally due to the program used (described in the Intervention Procedures). Observers measured OTR using a frequency count. 
Praise. Praise was defined as a verbal comment showing approval of a student's behavior over or above a simple acknowledgement of a correct response, this included behavior specific praise as well as general praise statements. Praise included verbal responses such as "Great job raising your hand!" or "Your handwriting is improving!" Non-examples included "Thank you." or "Alright." Observers used a frequency count to measure praise throughout each session. They tracked praise to an individual ("Billy, I like the way you did that sum!") separately from praise to a group ("Everyone is sitting quietly, great!").

Reprimands. Interactions scored as reprimands included admonishing a student, making negative statements about a student's social behavior, mention of negative consequences, or using comments intended to stop a student from misbehaving. Examples included, "I told you to be quiet." or "John, you need to stay in your seat." Observers used a frequency count to measure reprimands to individuals as well as reprimands to the group.

\section{Procedures}

The teacher used Level 4 of the Reading Mastery Signature Edition (RMSE; Engelmann, \& Hanner, 2008) program during the reading instruction. The RMSE program is research based and includes direct instruction with scripted OTR. The students engaged in tasks to accurately read words using specific phonics skills and to define vocabulary that would be included in the text. Observation during the program ensured that the students performed similar tasks throughout the phases of the intervention. Although the RMSE program had scripted OTR for the teacher to use, she controlled the rate of delivery with a MotivAider (Levinson, Kopari, \& Fredstrong, 2002), an electronic cueing device she wore which was set to vibrate at specific time intervals according to the intervention phase.

Baseline. During the baseline phase, the teacher did not have a specific behavior management system in place, allowing the dependent variables to be measured in an environment with little to no positive or negative reinforcement. The teacher did set a MotivAider to one-min intervals at which she gave an OTR. These baseline procedures measured the academic and behavioral performance of students without the CW-FIT intervention. During this phase the teacher gave an average of 1.16 OTR to the group per min.

Intervention phases. In this study two separate intervention conditions were compared: CW-FIT with low OTR and CW-FIT with high OTR.

CW-FIT with low OTR. The teacher directly taught the CW-FIT social skills (a) get the teacher's attention appropriately (b) follow directions the first time, and (c) ignore inappropriate behaviors (Wills et al., 2010). These skills were taught in three 10-min lessons using direct instruction with teacher modeling, teacher-student and student-student role-plays, practice, and review. The social skills, with corresponding steps, were posted on the board. The teacher reviewed the skills at the beginning of class during the intervention phases.

Because of the small number of students in the class, each student was his own team (independent group contingency), as done by Trevino-Maack, Kamps, and Wills (2015), rather than participating on a team of two to five students, which is the general practice for CW-FIT. All of the one-student teams were working for the same reward. During CW-FIT the teacher determined a criterion or set number of points a student must earn during the lesson to receive a reward. During the CW-FIT session the teacher set a timer to ring every two to three min. At each beep of the timer, the teacher gave praise and awarded points to each student who was engaged in appropriate behaviors as outlined by the posted social skills. At the end of the lesson each student who had met the previously determined criterion was given the reward (e.g., 2-min free time, painting, music, games, stickers, prizes).

During this intervention the MotivAider was set at one-min intervals to signal the teacher to give an OTR, as during baseline. This allowed for the effects of CW-FIT with low OTR to be measured and ensured that the OTR rates were not a conflicting variable in comparison to baseline. The teacher gave on average 1.11 OTR per min during this phase of the study.

CW-FIT with high OTR. The teacher used CW-FIT in this phase as outlined in the previous section but with high rather than low OTR. The MotivAider signaled the teacher to give an OTR at 15 -sec intervals. The teacher gave on average 6.22 OTR per min during this phase of the study.

\section{Research Design}

This study used an alternating treatment design, enabling comparison of two treatments within a single subject (Cooper, Heron, \& Heward, 2007). This began with a baseline phase to show the rates of the dependent variables without intervention. During the second phase, the study alternated between conditions (CW-FIT with low or CW-FIT with high OTR) in the form of a multi-element design. The intervention shown to be most effective was used in the final phase.

\section{Results}

Derek

Active engagement. As seen in Figure 1, some variability was apparent in Derek's active engagement within phases; however, no overlap occurred between the baseline and CW-FIT with high OTR phases. During CW-FIT with low OTR Derek's active engagement trended downward; in the high OTR phase the active engagement had an upward trend. Thus, CW-FIT with high OTR resulted in the highest levels of active engagement. Derek's active engagement increased significantly from an average of $28.60 \%$ during baseline to $50.53 \%$ during CW-FIT with low OTR, and ultimately to $78.08 \%$ during CW-FIT with high OTR.

Disruptive behavior. During baseline, Derek had significantly higher levels of disruptive behavior than during either intervention phase. There was some overlap between intervention phases, but ultimately CW-FIT with high OTR seemed to result in a greater decrease in disruptive behaviors: from a baseline average rate per min of 3.13 instances to 1.78 instances in the CW-FIT with low OTR phase and 0.75 in the CW-FIT with high OTR phase.

Correct responses. Similarly, Derek showed a lower level of correct responses during the baseline phase in comparison to intervention phases. CW-FIT with high OTR showed a stable level of performance, resulting in the highest percentage of correct responses. Derek's correct responses increased from an average baseline rate of $76.79 \%$ to $88.70 \%$ during the CW-FIT with low OTR phase and $96.65 \%$ during the CWFIT with high OTR phase.

\section{Joshua}

Active engagement. Joshua's active engagement rates showed distinct differences in levels, as shown in Figure 2. CW-FIT with high OTR resulted in the highest rates of active engagement in comparison to baseline and CW-FIT with low OTR. Joshua's active engagement increased substantially from an average of $21.17 \%$ during baseline and $34.75 \%$ during the CW-FIT with low OTR phase to $79.17 \%$ during the CW-FIT with high OTR phase. 

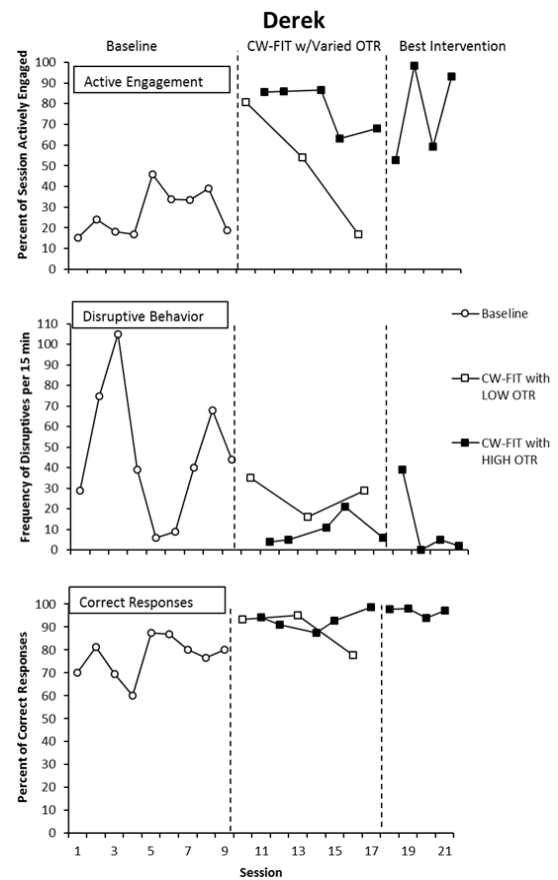

Figure 1. Derek's active engagement, disruptive behavior, and correct responses. Active engagement was calculated by minutes actively engaged/minutes of session $\times 100$ graphed as the percentage of the observation that the student was actively engaged. Disruptive behaviors are graphed as the number of occurrences during the 15 min session. Correct responses were calculated as correct responses/(correct responses +incorrect responses + non-responses) $\times 100$ graphed as a percentage.
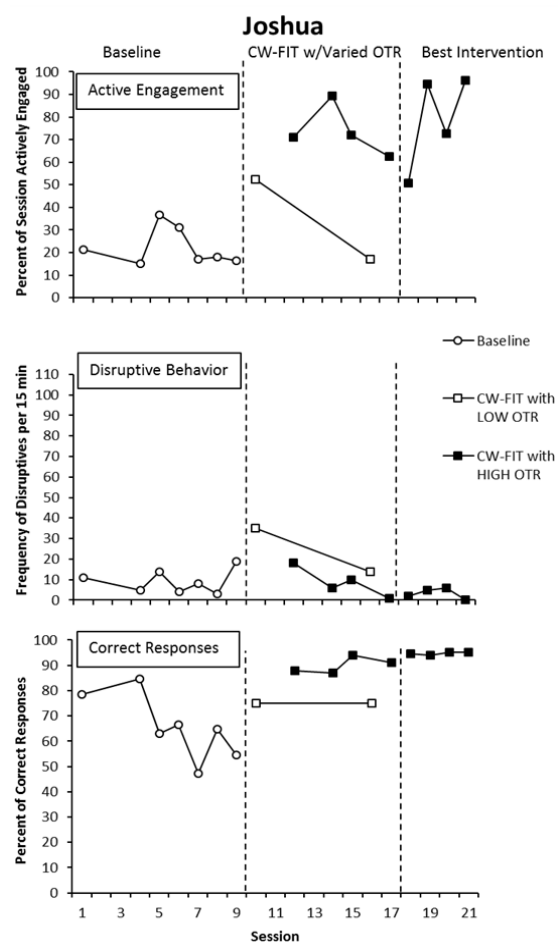

Figure 2. Joshua's active engagement, disruptive behaviors, and correct response. Active engagement was calculated by minutes actively engaged/minutes of session $\times 100$ graphed as the percentage of the observation that the student was actively engaged. Disruptive behaviors are graphed as the number of occurrences during the 15 min session. Correct responses were calculated as correct responses/(correct responses +incorrect responses + non-responses) $\times 100$ graphed as a percentage.

Disruptive behaviors. Some overlap was noted between phases for Joshua's disruptive behaviors. These behaviors appeared to increase with the initial implementation of the intervention phases, which created most of the overlap. Despite this initial increase $(0.72$ instances per min during baseline to 1.63 in the low OTR phase), rates stabilized over sessions, showing a greater decrease with the use of CW-FIT with high OTR (0.35 instances per min).

Correct responses. Throughout baseline Joshua's correct responses appeared to trend downward. With the implementation of the intervention phases, Joshua's percentage of correct responses increased and remained at stable levels. CW-FIT with high OTR yielded the highest number of correct responses, which had increased from a baseline average rate of $76.79 \%$ to $88.70 \%$ during the CW-FIT with low OTR phase and $96.65 \%$ during the CW-FIT with high OTR phase.

\section{Trent}

Active engagement. Trent's active engagement appeared to overlap during the initial implementation of the interventions, as seen in Figure 3. This continued until Trent's third session of the CW-FIT with low OTR phase, which showed a dramatic decrease. Despite this outlier, the effects on engagement appeared to separate over sessions, with the CW-FIT with high OTR phase showing the highest levels of active engagement. There was an increase from an average of $32.70 \%$ during baseline to $54.77 \%$ during the low OTR phase and $83.60 \%$ during the high OTR phase.
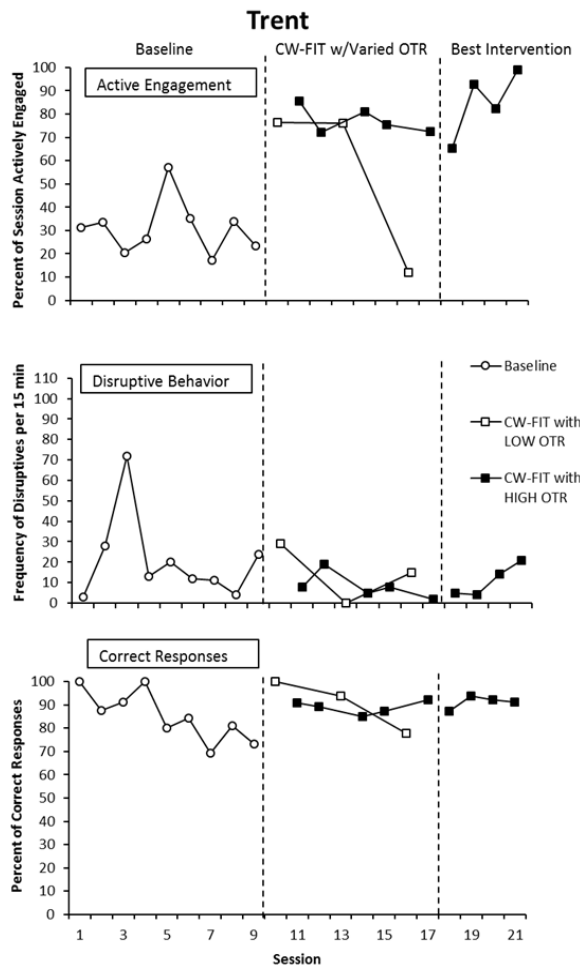

Figure 3. Trent's active engagement, disruptive behaviors, and correct response. Active engagement was calculated by minutes actively engaged/minutes of session $\times 100$ graphed as the percentage of the observation that the student was actively engaged. Disruptive behaviors are graphed as the number of occurrences during the $15 \mathrm{~min}$ session. Correct responses were calculated as correct responses/(correct responses +incorrect responses + non-responses) $\times 100$ graphed as a percentage.

Disruptive behaviors. Trent's disruptive behaviors showed more overlap between phases, though his levels were higher during baseline than during the intervention phases. The overlap between intervention phases created difficulty in visually determining which intervention was most effective. Based on averages, CW-FIT with high OTR was most effective in decreasing Trent's disruptive behaviors, which decreased from an average per min rate of $1.45 \mathrm{in}$ - 
stances during baseline to 0.98 in the CW-FIT with low OTR phase and 0.61 with the CW-FIT with high OTR intervention.

Correct responses. During baseline Trent's number of correct responses was initially at a very high level, but trended downward over time. Both interventions showed high levels of correct responses. But similar to baseline, Trent's pattern of correct responses trended downward over sessions during the CW-FIT with low OTR phase, becoming most stable during CW-FIT with high OTR. Trent's baseline rate for correct responses was $85.07 \%$, increasing to $90.51 \%$ during the CW-FIT with low OTR phase and $92.37 \%$ during the CW-FIT with high OTR phase.

\section{Teacher Behaviors}

Praise. Patterns of increase with praise were very similar to patterns of increase with OTR. Higher levels of individual praise occurred during CW-FIT with high OTR than during baseline or CW-FIT with low OTR. Teacher praise rates for individuals increased from a baseline average of 0.07 praise statements per min to 0.17 during the CW-FIT with low OTR phase and 0.91 in the high OTR phase. Also group praise rates continuously trended upward, increasing from an average of 0.29 praise statements per min during baseline to 0.57 during CW-FIT with low OTR and 3.34 following the increase to high OTR.

Reprimands. The teacher's individual reprimands decreased with CW-FIT with low OTR for Derek and Joshua and decreased further with the use of CW-FIT with high OTR. Individual reprimand rates to Trent increased with both phases of CW-FIT. Overall, teacher reprimand rates to individuals decreased from 0.39 reprimands per min during baseline to 0.26 during low OTR and eventually to 0.12 during the high OTR phase. Teacher reprimand rates to the group decreased slightly from 0.19 per min during baseline to 0.10 during CW-FIT with low OTR and 0.15 during CW-FIT with high OTR.

\section{Overall Effects}

The implementation of CW-FIT increased active engagement for all three students, as seen in Figures 1, 2, and 3. Additionally, Derek and Trent decreased their disruptive behaviors, although Joshua's disruptive behaviors increased. All students increased their number of correct responses when CW-FIT was in use. Greater improvement was seen in all areas with CW-FIT with high OTR: All three students increased their active engagement and correct responses and decreased their disruptive behaviors during this phase.

\section{Social Validity}

All students communicated on the social validity questionnaire that they liked playing CW-FIT because they had the opportunity to "earn prizes" and they thought the "game was fun." All students reported other students should get to play CW-FIT "because it's fun." When asked what they didn't like about CW-FIT, two students reported "nothing." The third reported, "I'm very busy." His comment seemed to be referring to the fact that CW-FIT was keeping him academically engaged.

\section{Discussion}

With the implementation of the CW-FIT there was an immediate improvement in active engagement and correct responses for three elementary students with developmental disabilities in this special education small group setting. However, these levels showed a descending trend over time. In the phase of CW-FIT with low OTR, levels were similar to those during baseline, indicating that CW-FIT alone may not maintain high enough levels of active engagement and correct responses for students with disabilities. CW-FIT may create initial change in behavior for students with disabilities, but academic interventions may need to be added to maintain high levels of active engagement and correct responses over time.

During baseline, students' disruptive behaviors were variable. CW-FIT with low OTR showed lower disruptive behavior levels with less variability than baseline. These data support previous studies conducted in elementary general education classrooms, which also showed decreases in disruptive behaviors with CW-FIT (Caldarella et al., 2015; Kamps et al., 2015; Kamps et al., 2011; Wills et al., 2014).

The combination of CW-FIT and high OTR resulted in higher levels of active engagement, fewer disruptive behaviors, and higher levels of correct responses in comparison to baseline and to CW-FIT with low OTR, supporting the effectiveness of high OTR on academics and behavior (Carnine, 1976; Conroy et al., 2009; Skinner \& Shapiro, 1989; Sutherland et al., 2003; West \& Sloane, 1986). This intervention also resulted in the highest levels of teacher praise, supporting the correlation of OTR and praise (Sutherland et al., 2002).

This study demonstrates that CW-FIT can be used in a small group setting with elementary students with developmental disabilities to support instruction and behavior management. With CW-FIT and high OTR, students were actively engaged, effectively responsive, and appropriately behaved. Students with developmental disabilities need a behavior management program like CW-FIT, in combination with solid academic instruction with high OTR, to experience optimal behavioral and academic outcomes.

\section{Limitations and Areas for Future Research}

Some limitations must be considered when interpreting the results of this study. The number of participants and types of disabilities were limited, while their ages and academic ability varied. Further, CW-FIT traditionally uses an interdependent group contingency with two to five students on a team. In this study, we used an independent group contingency with one student on each team. Further research is needed to determine if individual teams are more appropriate for students with developmental disabilities or if interdependent group contingencies further improve behavior. Though IOA was calculated using MOOSES, it was not collected for the treatment fidelity checklist.

Another limitation is that Joshua had missing data points due to absences, which limits the ability to draw conclusions from his data. There also was minimal data points for all participants in the low OTR condition. The researchers moved to the most effective phase due to the negative behaviors observed in this condition. Additionally, this study was conducted during a summer program of only six weeks. Due to the time constraints, there was no return to baseline. Likewise, CW-FIT was not removed in order to measure the effects of high OTR with no formal behavioral management system, bringing into question whether the same positive results would occur with high OTR as the only intervention. The challenging behavior of the students and their high motivation to earn the rewards from CW-FIT seem to predict that the students would lack motivation to respond and follow rules without CW-FIT. However, this aspect was not investigated in this study. These limitations may impact the generalization of its findings.

Future research should include replication of this intervention with more participants with additional disability classifications (e.g., EBD, specific learning disabilities) in small group special education settings in elementary and secondary schools, as well as across academic subjects (e.g., math, 
writing). Horner et al. (2005) suggested that interventions supported by single-case studies should be conducted in five separate settings with 20 different subjects in order to demonstrate to be considered an evidence-based practice. Additional research may include removing CW-FIT and using only high OTR to better understand the limitations of CW-FIT with students with disabilities. Future research should address the impact of CW-FIT on academic performance of students with and without disabilities by using curriculum-based measures or state testing.

\section{Conclusions and Implications for Practice}

Students with developmental disabilities need behavior management systems to decrease disruptive behavior and increase engagement. These students also need engaging instruction that gives them OTR to improve academic performance. This study demonstrated the effectiveness of CW-FIT, a behavior management program, delivered in combination with high OTR to help improve behavior and academic performance of elementary students with developmental disabilities. CW-FIT with high OTR resulted in higher levels of active engagement and correct responses as well as fewer disruptive behaviors in comparison to CW-FIT with low OTR. Results suggest that teachers in special education classrooms can use CW-FIT with high OTR to manage elementary students' disruptive behavior and to increase their ability to respond correctly.

\section{Acknowledgement}

The research reported in this article was supported in part by a grant from the Institute of Education Sciences and the U.S. Department of Education (R324A120344), awarded to the University of Kansas in cooperation with Brigham Young University and Vanderbilt University. The opinions presented in this article are those of the authors, and no endorsement by the agency is intended or implied.

\section{References}

Ashburner, J., Ziviani, J., \& Rodger, S. (2010). Surviving in the mainstream: Capacity of children with autism spectrum disorders to perform academically and regulate their emotions and behavior at school. Research in Autism Spectrum Disorders, 4, 18-27. doi:10.1016/j.rasd.2009.07.002

Caldarella, P., Williams, L., Hansen, B. D., \& Wills, H. (2015). Managing student behavior with Class-Wide Function-Related Intervention Teams: An observational study in early elementary classrooms. Early Childhood Education Journal, 43, 357-365. doi:10.1007/ s10643-014-0664-3

Carnine, D. W. (1976). Effects of two teacher-presentation rates on off-task behavior, answering correctly, and participation. Journal of Applied Behavior Analysis, 9, 199-206. doi:10.1901/jaba.1976.9-199

Carr, E. G., Taylor, J. C., \& Robinson, S. (1991). The effects of severe behavior problems in children on the teaching behavior of adults. Journal of Applied Behavior Analysis, 24, 523-535. doi:10.1901/jaba.1991.24523

Conroy, M., Sutherland, K., Haydon, T., Stormont, M., \& Harmon, J. (2009). Preventing and ameliorating young children's chronic problem behaviors: An ecological classroom based approach. Psychology in the Schools, 46, 3-17. doi:10.1002/pits.20350

Coogan, B. A., Kehle, T. J., Bray, M. A., \& Chafouleas, S. M. (2007). Group contingencies, randomization of reinforcers, and criteria for reinforcement, self-monitoring, and peer feedback on reducing inappropriate classroom behavior. School Psychology Quarterly, 22, 540-556.

Cooper, J. O., Heron, T. E., \& Heward, W. L. (2007). Applied behavior analysis (2nd Ed.). Columbus, OH: Pearson.

Desrochers, M. N., \& Fallon, M. (2014). Instruction in Functional Assessment. Geneseo, NY: Open SUNY Textbooks.

Engelmann, S., \& Hanner, S. (2008). Reading Mastery Signature Edition. Columbus, OH: SRA/McGraw-Hill.

Hammill, D. D., Pearson, N. A., \& Weiderholt, J. L. (1996). The Comprehensive Test of Nonverbal Intelligence. Austin, TX: Pro-ed.

Horner, R. H., Carr, E. G., Halle, J., McGee, G., Odom, S., \& Wolery, M. (2005). The use of single-subject research to identify evidence-based practice in special education. Exceptional Children, 71, 165-179. doi:10.1177/001440290507100203

Individuals With Disabilities Education Act, 20 U.S.C. § 1400 (2004).

Kamps, D. M., Tankersley, M., Ellis, C. (2000). Social skills interventions for young at-risk students: A 2-year follow-up study. Behavioral Disorders, 25, 310-324.

Kamps, D., Wills, H. P., Dawson-Bannister, H., Heitzman-Powell, L., Kottwitz, E., Hansen, B., \& Fleming, K. (2015). Class-Wide Function-Related Intervention Teams "CW-FIT" efficacy trial outcomes. Journal of Positive Behavior Interventions, 17, 134-145. doi:10.1177/1098300714565244

Kamps, D., Wills, H. P., Heitzman-Powell, L., Laylin, J., Szoke, C., Petrillo, T., \& Culey, A. (2011). Class-wide function-related intervention teams: Effects of group contingency programs in urban classrooms. Journal of Positive Behavior Interventions, 13, 154-167. doi:10.1177/1098300711398935

Kennedy, C. (2005). Single-case designs for educational research. Boston, MA: Pearson Education, Inc.

Levinson, S., Kopari, J., \& Fredstrom, J. (2002). Helping kids change their behavior: The helper's guide to the MotivAider method. Thief River Falls, MN: Behavioral Dynamics.

Lewis, T. J., Hudson, S., Richter, M., \& Johnson, N. (2004). Scientifically supported practices in emotional and behavioral disorders: A proposed approach and brief review of current practices. Behavioral Disorders, 29, 247-259.

Lien-Thorne, S. \& Kamps, D., (2005). Replication study of the First Step to Success early intervention program. Behavioral Disorders, 31, 19-33.

MacSuga-Gage, A. S., \& Simonsen, B. (2015). Examining the effects of teacher-directed opportunities to respond on student outcomes: A systematic review of the literature. Education and Treatment of Children, 38, 211-239. doi:10.1353/etc.2015.0009

Nelson, J. R., Martella, R C., \& Galand, B. (1998). The effects of teaching school expectations and establishing a consistent consequence on formal office disciplinary actions. Journal of Emotional and Behavioral Disorders, 6, 153-163. 
Reschly, A. L., \& Christenson, S. L. (2006). Prediction of dropout among students with mild disabilities: A case for the inclusion of student engagement variables. Remedial and Special Education, 27, 276-292. doi:10.117 7/07419325060270050301

Reynolds, C.R. \& Kamphaus, R.W. (2006). BASC-2: Behavior Assessment System for Children (2nd ed.). Upper Saddle River, NJ: Pearson Education, Inc.

Skinner, C. H., \& Shapiro, E. S. (1989). A comparison of tapedwords and drill interventions on reading fluency in adolescents with behavior disorders. Education and Treatment of Children, 12, 123-133.

Stage, S. A., \& Quiroz, D. R. (1997). A meta-analysis of interventions to decrease disruptive classroom behavior in public education settings. School Psychology Review, 26, 333-368.

Sutherland, K. S., Alder, N., \& Gunter, P. L. (2003). The effect of varying rates of opportunities to respond to academic requests on the classroom behavior of students with EBD. Journal of Emotional and Behavioral Disorders, 11, 239-248. doi:10.1177/1063426603011 0040501

Sutherland, K. S., \& Wehby, J. H. (2001). Exploring the relationship between increased opportunities to respond to academic requests and the academic and behavioral outcomes of students with EBD. Remedial and Special Education, 22, 113-121. doi:10.1177/074193250102200205

Sutherland, K. S., Wehby, J. H., \& Yoder, P. J. (2002). Examination of the relationship between teacher praise and opportunities for students with EBD to respond to academic requests. Journal of Emotional and Behavioral Disorders, 10, 5-13. doi:10.1177/106342660201000102

Tapp, J., Wehby, J., \& Ellis, D. (1995). A multiple option observation system for experimental studies: MOOSES. Behavior Research Methods, Instruments, \& Computers, 27, 25-31. doi:10.3758/BF03203616

Thorne, S., \& Kamps, D. (2008). The effects of a group contingency intervention on academic engagement and problem behavior of at-risk students. Behavior Analysis in Practice, 1, 12-18.

Trevino-Maack, S. I., Kamps, D., \& Wills, H. (2015). A group contingency plus self-management intervention targeting at-risk secondary students' class-work and active engagement. Remedial and Special Education, 36, 347-360. doi:10.1177/0741932514561865

U.S. Department of Education. (2008). 30th annual report to Congress on the implementation of the Individuals with Disabilities Education Act, 2008. Washington, DC: U.S. Department of Education, Office of Special Education Programs.

Wechsler, D., Kaplan, E., Fein, D., Kramer, J., Morris, R., Delis, D., \& Maelender, A. (2003). Wechsler Intelligence Scale for Children (4th ed.). San Antonio, TX: Pearson.

West, R. P., \& Sloane, H. N. (1986). Teacher presentation rate and point delivery rate: Effects on classroom disruption, performance accuracy, and response rate. Behavior Modification, 10, 267-286. doi:10.1177/01454455860103001
Wills, H. P., Iwaszuk, W. M., Kamps, D., \& Shumate, E. (2014). CW-FIT: Group contingency effects across the day. Education and Treatment of Children, 37, 191-210. doi:10.1353/etc.2014.0016

Wills, H. P., Kamps, D., Hansen, B., Conklin, C., Bellinger, S., Neaderhiser, J., \& Nsubuga, B. (2010). The classwide function-based intervention team program. Preventing School Failure: Alternative Education for Children and Youth, 54, 164-171. doi:10.1080/10459880903496230

Woodcock, R. W., McGrew, K. S., \& Mather, N. (2001). Woodcock-Johnson III Tests of Achievement. Itasca, IL: Riverside Publishing. 